\title{
A (IM)POSSIBILIDADE DO HABEAS CORPUS COLETIVO NO ORDENAMENTO JURÍDICO BRASILEIRO
}

\section{THE (IM) POSSIBILITY OF THE COLLECTIVE HABEAS CORPUS IN THE BRAZILIAN LEGAL ORDER}

\author{
Brunna Leles Fernandes ${ }^{1}$ \\ Islane Archanjo Rocha²
}

\section{RESUMO}

O presente estudo tem como objeto a análise do instituto do habeas corpus na modalidade coletiva. $\mathrm{O}$ estudo girou em torno da possibilidade de proteção do direito à liberdade de locomoção de forma coletiva no ordenamento jurídico brasileiro. Muito embora o habeas corpus seja previsto na Constituição Federal e regulamentado pelo Código de Processo Penal, não há previsão em sua modalidade coletiva. Tendo em vista a sociedade atual, sendo ela caracterizada como sociedade de risco o qual se faz menção no devido trabalho, as ofensas aos direitos fundamentais são cada vez mais frequentes e atingem proporções coletivas, desse modo, é importante que haja um instrumento que seja compatível para a tutela de tais direitos. Logo, a partir dos estudos, foi possível concluir que a jurisprudência brasileira caminha em direção ao entendimento de que é cabível o referido remédio em defesa da coletividade. A temática é relevante pois demonstra que tal aplicabilidade diminuirá o percentual do encarceramento em massa de mulheres sob o pálio da prisão preventiva, uma vez aplicado o remédio na modalidade coletiva, assegurará a dignidade das mães de crianças até 12 anos, gestantes e crianças do precário e insalubre sistema prisional brasileiro.

Palavras-chave: Habeas Corpus Coletivo; Liberdade; Sociedade de Risco.

\section{ABSTRACT}

\footnotetext{
${ }^{1}$ Graduada em Direito pela Universidade Vale do Rio Doce. E-mail: brunna_lelis@hotmail.com ORCID: https://orcid.org/0000-0002-6055-5556

2 Professora Mestre em Gestão Integrada do Território. Pós-graduada em Direito Público. Pós-graduada em Direito Penal e Processo Penal. Graduada em Direito. Professora do Curso de Direito da Universidade Vale do Rio Doce. E-mail: islane.rocha@univale.br, Governador Valadares, Brasil. ORCID: https://orcid.org/0000-0002-6132-5488
} 
The present study aims to analyze the habeas corpus institute in the collective modality. The study revolved around the possibility of protecting the right to freedom of movement collectively in the Brazilian legal system. Although habeas corpus is provided for in the Federal Constitution and regulated by the Penal Procedure Code, there is no provision in its collective modality. Bearing in mind the current society, being characterized as a risk society which is mentioned in due work, offenses against fundamental rights are increasingly frequent and reach collective proportions, therefore, it is important that there is an instrument that is compatible for the protection of such rights. Therefore, from the studies, it was possible to conclude that Brazilian jurisprudence is moving towards the understanding that the aforementioned remedy is appropriate in defense of the community. The theme is relevant because it demonstrates that such applicability will decrease the percentage of mass incarceration of women under the canopy of preventive prison, once the remedy is applied in the collective modality, it will ensure the dignity of mothers of children up to 12 years old, pregnant women and precarious children and unhealthy Brazilian prison system.

Keywords: Habeas Corpus Coletivo; Freedom; Risk Society.

\section{INTRODUÇÃO}

O direito de locomoção é uma garantia fundamental tendo previsão na Constituição Federativa do Brasil. Esta estabelece a prerrogativa do indivíduo se locomover em território nacional, possuindo o direito de nele entrar, sair ou permanecer em tempos de paz. Esse direito é concebido pela doutrina sendo de primeira geração (ou dimensão), em razão que, foram os primeiros direitos a serem conquistados pela sociedade e positivados pelo ordenamento jurídico.

Seu surgimento se deu com a gêneses da Magna carta de 1215, sendo imposta pelos nobres ao Rei de Inglaterra, Rei João Sem-Terra, para que respeitasse as liberdades mínimas dos cidadãos.

Tendo em vista a sociedade atual, a coletividade vê-se sujeita a riscos inerentes às consequências da modernização globalizada. As produções em massa e as novas tecnologias produzidas deixam resquícios no planeta que não se pode mensurar e afetam a coletividade por inteira, sem respeitar limite algum. Desse modo, 
vê-se a necessidade de existir instrumentos no ordenamento jurídico que tutelem os interesses coletivos para que se adapte com a proporção coletiva que os riscos alcançam.

Isso posto, como objeto de estudo do presente artigo tem-se a seguinte indagação: é cabível habeas corpus coletivo no ordenamento jurídico brasileiro? A fim de compreender a hesitação, buscou-se comprovar se há expectação de proteção do direito à liberdade de locomoção na modalidade coletiva.

Torna-se oportuno expor a ideia individualista do direito de locomoção e do instituto do habeas corpus, além de prover base jurídica para comprovar a utilização do writ no âmbito coletivo. Outrossim, buscou-se retratar, de forma exploratória, a respeito da possibilidade de utilização do habeas corpus individual ou coletivo no caso de mães e gestantes presas, na decisão HC 143.641.

Com o interesse de auferir o designo pautado nesse estudo, foi usada como metodologia a revisão bibliográfica, bem como a pesquisa jurisprudencial. Este trabalho se valeu de doutrinas que elucidam a acerca do tema, da Constituição Federal de 1988, a qual prevê o habeas corpus como garantia constitucional, o Código de Processo Penal e demais leis pertinentes ao caso.

O exposto artigo busca possibilitar ao legente conhecimentos relevantes acerca do habeas corpus tais como, o conceito, finalidade e evolução histórica. Sucessivamente, apresenta o tal instrumento como garantia fundamental, expondo sua relevância para a tutela dos direitos coletivos.

O conteúdo exposto no artigo apresenta notável relevância, pois faz referência a um instrumento que, apesar de não estar positivado na modalidade coletiva, tem sido crucial para tutelar os direitos coletivos, os quais na prática atual têm sido atacados a cada dia com mais periodicidade.

\section{HABEAS CORPUS}




\subsection{HISTÓRIA DO HABEAS CORPUS}

Parafraseando Heráclito Antônio Mossin (1995), o Habeas Corpus teve menção frente ao ordenamento jurídico logo após a ida de D. João VI para Portugal, firmado pelo conde dos Arcos, no Decreto de 23 de maio de 1821, sendo conhecido esse decreto como "Nossa Magna Carta", o qual possuía o objetivo de proteção a liberdade física do homem. Portanto, cabe lembrar que o Habeas Corpus não era desconhecido no Brasil, apenas não fazia jus ao nome que se menciona nos tempos de hoje.

Mauro Cunha (1985) retrata da constituição Imperial de 1824, sendo a primeira constituição brasileira, não fazia menção ao Habeas Corpus, porém, tutelava o direito de ir e vir e ficar do cidadão.

A expressão Habeas Corpus, conforme Heráclito Antônio Mossin (1995) destacou-se em nosso ordenamento jurídico como Código Criminal de 1830, em seus artigos 183-188. Sua regulamentação teve origem no ano de 1832 , com previsão no art. 340, o qual expressava que, todo cidadão que entender que ele ou outrem sofre prisão ou constrangimento ilegal em sua liberdade tem direito de pedir ordem de Habeas Corpus a seu favor.

Dessa forma, como retrata o autor Pontes de Miranda (2007), o Código de Processo de 1832 também elencou como deveria ser o pedido de Habeas Corpus, sendo esse feito por meio de petição, devidamente fundamentada, tendo em vista que, era dever do requerente apresentar as razões em que se fundava a persuasão da ilegalidade da prisão.

Naquela época, o Habeas Corpus tanto nos casos de denegação ou concessão, se dava de forma definitiva e irrecorrível, existindo apenas uma instância. Com isso, Pontes de Miranda (2007) faz menção das modificações que ocorreu nas leis, que se tratava de habeas corpus, entre meio os anos de 1832 e 1871.

Aury Lopes Jr. (2014) enfatiza que o Habeas Corpus não teve seu surgimento no Brasil, apesar de boa parte dos doutrinadores entenderem que a criação e o surgimento do Habeas Corpus surgiu do Direito Anglo-saxão, o qual serviu de 
inspiração para os demais países. De outro modo, entende-se que os principais antecedentes históricos dessa garantia Constitucional, nasceram do Direito aragonês, e posteriormente do Direito Inglês.

Não restando dúvidas de que esses marcos históricos foram decisivos para o progresso do Estado Democrático de Direito e na proteção de liberdade individual frente a prisão ilegal.

De tal modo, nota-se que a Constituição da República, em seu artigo 5º, inciso LXVIII, fomentou o habeas corpus de forma ampla, abrangendo tanto a esfera repressiva quanto a preventiva, asseverando a importância da preservação do nosso direito de locomoção.

\subsection{Conceito e Espécies}

Tendo a gênese no léxico latim, Habeas Corpus denota em sentido literal "tome o corpo", palavra a qual tem por objeto constitucional a proteção da liberdade física e locomotora do cidadão. Segundo o entendimento de Ferreira $(1088$, p. 6) "Ter corpo, ou tomar o corpo, é uma metáfora, que significa a liberdade de ir e vir, o poder de locomoção, o uso dessa liberdade de locomoção livremente, salvo restrições legais a todos impostas indistintamente."

Nesse sentido, o habeas corpus, é um dos direitos constitucionais primários, tendo em vista que, sem esse direito fica impossível exercer os demais previstos na Constituição, conforme preceitua tal dispositivo.

Visto que o Habeas corpus é conhecido de forma internacional como afirma Pontes de Miranda (2007) sendo um instrumento de defesa do direito fundamental de liberdade e de locomoção, sua eficácia se dá de forma plena, o qual se garante a aplicabilidade de forma imediata.

Sua previsão legal se estabelece no art. 5. ${ }^{\circ}$ da Constituição Federal, em seu inciso LXVIII, sendo uma ferramenta jurídica colocada à disposição de um determinado indivíduo, o qual sofre ou se sente ameaçado de sofrer violência ou coação em sua liberdade de locomoção, por ilegalidade ou abuso de poder. 
Seguindo esse mesmo pensamento, o Supremo Tribunal Federal emitiu a Súmula 695, que possui a seguinte dicção: "o Habeas Corpus não caberá nos casos de punições disciplinares, ou quando já extinta a pena privativa de liberdade".

Outrossim, esse remédio heroico tem previsão legal a partir do artigo 647, do Código de processo Penal, refuta-se atos administrativos ou atos judiciários, coisa julgada e de particulares.

Por conseguinte, Aury Lopes Jr (2012) traz a denominação de Habeas Corpus repressivo e suspensivo, conforme afirma tal doutrinador, designa-se liberatório ou repressivo, quando o habeas corpus tem por escopo a sujeição ilegal à liberdade de locomoção já existente, visando suprimir o constrangimento ou coação de uma determinada pessoa que se encontra presa por ilegalidade ou abuso de poder. Portando, quando prestado, expede-se um alvará de soltura e o preso é posto em liberdade.

Logo denomina-se habeas corpus preventivo ou suspensivo, quando houver uma situação proeminência de sofre violência ou coação na sua liberdade ambulatória por ilegalidade ou abuso de poder. Provido o remédio, expede-se um salvo-conduto e, através deste, o paciente recebedor do remédio fica interditado de ser privado de sua liberdade pelo fato que resultou a apreciação do writ pela autoridade prevista.

No que se refere a sua natureza jurídica, possui previsão no Livro III do Código de Processo Penal, capítulo X, o qual se faz menção dos Recursos em Geral, vale ressaltar que apesar de estar na parte de recursos o Habeas Corpus não possui tal natureza de recurso, e sim, uma ação autônoma de impugnação, o qual se faz necessário afastar ou cessar a violência ou ameaça na liberdade de locomoção por ilegalidade ou abuso de poder.

De tal modo, para José Antônio Pimenta Bueno no ano de 1922, conforme citado por Heráclito Antônio Mossin (1995, p.63) entende-se que Habeas Corpus constituía um verdadeiro recurso.

Entretanto, (Sady Cardoso Gusmão apud Cunha, Silva, 1985, p. 69) não se faz presente de tal afirmativa, uma vez que a amplitude do Habeas Corpus não pode ser submetida ao rigor exigido pelos instrumentos recursais. 
Por tanto, essa garantia Constitucional de locomoção, o qual se trata do Habeas Corpus, somente poderá haver um provimento, sendo ele declaratório e constitutivo. Essa garantia constitucional se define pela sua ampla legitimidade ativa, usada para sua impetração, a qual se faz cessar o efeito da capacidade civil ou postulatória do impetrante.

\section{HABEAS CORPUS COLETIVO}

Denomina-se como habeas corpus coletivo, a ação coletiva constitucional, com natureza de garantia constitucional fundamental, de aplicabilidade imediata e de interpretação ampla, oportuna para tutelar o direito de liberdade de locomoção em todas as suas dimensões, sejam difusas, coletivas ou situações individuais que hajam homogeneidade de questões de fato ou de direito, levando-se em consideração a summa divisio constitucionalizada proposta por Lílian Nássara (2015).

Apesar de inexistir previsão expressa no ordenamento jurídico brasileiro da modalidade coletiva do Habeas Corpus, a Corte Suprema brasileira inovou ao admitilo. A decisão vem adimplir uma lacuna no direito coletivo penal, uma vez que, na seara cível, já está consolidada a importância das demandas coletivas na jurisprudência e na legislação.

De tal modo, cabe ressaltar que a doutrina não tem se aprofundado sobre o tema, sendo o habeas corpus coletivo uma inovação que surgiu diante das novas necessidades da sociedade de risco emergente, em resguardar o direito de ir, vir e ficar dos cidadãos.

Seu surgimento se deu com a recente decisão no dia (20/02/2018), no HC 143.641/SP, o qual a $2^{\text {a }}$ Turma do Suprema Tribunal Federal, de forma inédita, concedeu ordem de habeas Corpus coletivo, determinando a substituição da prisão preventiva pela domiciliar a todas a mulheres presas, gestantes, puérperas ou mães de crianças, ou pessoas com deficiências, o que será tratado em tópico próprio.

O direito de liberdade de locomoção, ou de ir, vir e ficar, que está sendo violado ou ameaçado é referente ao alcance de uma coletividade, não sendo razoável, 
ou até mesmo viável, que cada pessoa atingida demandasse na Justiça individualmente, uma vez que estão submetidas a uma mesma situação.

Em harmonia com Gregório Assagra (2008), na presente atualidade a esse instituto se perfaz na existência de pluralidade de sujeitos, portanto, não se pode definir por si só um habeas corpus coletivo, sendo que não é apenas a natureza coletiva do direito que faz com que determinada ação seja considerada como coletiva, bastando-se a quantidade de sujeitos afetados.

$\mathrm{Na}$ verdade, pode-se comprovar os direitos individuais homogêneos, sendo que nesse caso os interesses são pertencentes a pessoas determinadas, sendo eles divisíveis. Constituem-se, assim, em direitos individuais, considerados coletivos somente no plano processual e recebem esse tratamento justamente em virtude da origem comum que possuem.

No mesmo sentindo, conforme afirma a Defensora pública Thais Lima (2016), não existe justificativa para que não inclua a tutela coletiva do status libertatis, uma vez que a violação dos direitos poderá atingir múltiplos sujeitos a partir de um ato danoso comum.

É importante ressaltar, nesse contexto, a visão do autor Ulrich Beck (2010), o qual salienta que a sociedade moderna se caracteriza, visando o desenvolvimento e os avanços tecnológicos e sociais trazidos pela sociedade industrial, com repercussões coletivas. Tratando-se, pois, de uma sociedade de risco. A sociedade industrial foi marcada pelo crescimento das classes médias, difusão do consumo de massa e, consequentemente, da sociedade de massa, potencializando a produção de riscos, que passou a atingir o ser humano e o meio ambiente como um todo.

Segundo Lilian Nássara (2015) a sociedade de risco é caracterizada pela distribuição igualitária dos riscos produzidos pela atividade humana, sem respeitar qualquer tipo de fronteira. Cabe lembrar que, a distribuição dos riscos não reflete sobre as diferenças sociais, econômicas e geográficas, e sim todos de forma análoga.

Anthony Giddens (1992), enfatiza que na modernidade e a confiança se refere ao conceito de risco, dado o desempenho das relações sociais que se caracteriza pelo avanço tecnológico, capacidade de destruição de bens individuais e 
coletivos, pelo deslocamento das relações no tempo e no espaço, até mesmo pela mudança de valores.

Portanto, à luz dos escritos de Lílian Nássara (2015), as ações coletivas na sociedade de risco nada mais são do que o reflexo da consubstancialização do Estado Democrático de Direito, que necessita constantemente satisfazer os interesses coletivos sociais mediante sua proteção, efetivando as garantias constitucionais e os preceitos de uma justiça social, que merece ser atendida no cotidiano do jurisdicionado.

\section{HABEAS CORPUS COMO INSTRUMENTO DE GARANTIA DA LIBERDADE DE LOCOMOÇÃO COLETIVA NA SOCIEDADE DE RISCO}

Como já mencionado na seção anterior, o habeas corpus coletivo surgiu devido as novas modalidades de sociedade existente nos dias hodiernos. Possui a mesma finalidade do habeas corpus, entretanto na modalidade coletiva, que abrange um grupo determinado, sendo o instrumento processual utilizado quando uma coletividade possui seu direito de liberdade e locomoção transgredido.

Tendo em vista que para José Afonso da Silva (2010) a liberdade tem um caráter histórico, uma vez que depende do poder do homem sobre a natureza, a sociedade e sobre si mesmo em cada momento da história. "A liberdade se amplia com a evolução da humanidade. Fortalece-se, estende-se, à medida que a atividade humana se alarga. Liberdade é conquista constante" (SILVA, 2010, p.232)

Com isso, nota-se a importância das tutelas coletivas para consagrar a proteção desses valores constitucionais firmados. Por envolverem garantias constitucionais, as tutelas coletivas não devem sofrer restrições, ainda mais diante de uma legitimidade mais ampla que a presente na tutela individual, garantindo, assim, mais efetividade aos direitos coletivos. 
Lilían Nássara (2015) ressalta que para entender a utilização do habeas corpus coletivo, deve-se entender os direitos coletivos, assim divididos em difusos, coletivos e individuais homogêneos.

A definição de interesses ou direitos difusos se estabelece no artigo 81, parágrafo único, inciso I, do Código de Defesa do Consumidor (CDC, 1990), o qual os define enquanto direitos "transindividuais, de natureza indivisível, de que sejam titulares pessoas indeterminadas e ligadas por circunstâncias de fato" .Explica Gregório Almeida (2008), que no plano de direito significa um interesse de dimensão coletiva, pertencente a uma comunidade de pessoas indeterminadas e indetermináveis, mas que é de um e de todos ao mesmo tempo.

Ressalta-se que, nesse caso, não há uma pregressa relação jurídica base entre as pessoas, sendo que elas estão ligadas mediante circunstância fática.

Isto posto, Lílian Nássara (2015) define que a liberdade de locomoção, sendo uma garantia constitucional, poderá ser tutelada de forma difusa, a despeito que, nada impede que a coação ou a ameaça de lesão a estes direitos tenha dimensão coletiva e que atinja uma comunidade de pessoas indeterminadas, criando a relação fática entre elas.

No que tange aos direitos coletivos em sentido estrito, estes estão previstos no artigo 81, parágrafo único, inciso II do Código de Defesa do Consumidor, definidos como "transindividuais de natureza indivisível de que seja titular grupo, categoria ou classe de pessoas ligadas entre si ou com a parte contrária por uma relação jurídica base". Insta salientar que os referidos direitos concernem a um grupo, uma categoria ou classe de pessoas indeterminadas, mas determináveis.

Em virtude, de ameaça ou lesão aos direitos de liberdade e locomoção poderá atingir um grupo, categoria ou classe, de forma indivisível, considerando-se a relação jurídica base, devendo o habeas corpus coletivo ser usado para estabelecer a garantia de locomoção.

Noutro giro, os direitos individuais homogêneos se definem mediante o artigo 81, parágrafo único, inciso III, do Código de Defesa do Consumidor, sendo aqueles decorrentes de origem comum. 
Nesse caso, os titulares desse direito são individualizados, podendo ser indeterminados, ou determinados. Os direitos são divisíveis e é possível ser discernidos os seus titulares. O direito individual homogêneo é coletivo, ou seja, é uma espécie de direito coletivo, em que os indivíduos são sempre mais de um e determinados.

$\mathrm{Na}$ presunção do direito individual homogêneo, a ação judicial é grupal, não intervindo o titular do direito subjetivo individual. Se este quiser promover ato judicial por conta própria para a proteção de seu direito individual pode fazê-lo, não afastando em nada a ação coletiva.

\section{ANÁlISE SOBRE A (IM)POSSIBILIDADE DO HC COLETIVO NO ORDENAMENTO JURÍDICO BRASILEIRO: CASO HC 143.641}

Tendo em vista o acima exposto, considerando toda natureza e objetivo do instituto do habeas corpus, no ordenamento jurídico brasileiro, membros do Coletivo da Advocacia em Direitos humanos (CADHu) em conjunto com a Defensoria Pública da União, entraram com pedido de habeas corpus coletivo frente ao Supremo Tribunal Federal (STF), no segundo semestre de 2017. Foi pedida a concessão do determinado remédio na modalidade coletiva, o qual determina a substituição da prisão preventiva por domiciliar de mulheres presas, em todo território nacional; que sejam gestantes ou mãe de crianças de até 12 anos ou de pessoas com deficiências, sem prejuízo da aplicação das medidas alternativas prevista no artigo 318 do Código de Processo Penal (CPP).

Outrossim, além da manifestação da Procuradoria-Geral da República, foi requerido a solicitação às autoridades judiciárias apontadas como coatoras, de informações sobre as mulheres que se enquadram como pacientes do referido Habeas Corpus.

Arrazoaram no mérito que ao serem recolhidas, mesmo que provisoriamente, em estabelecimentos prisionais, Ihe tem negado acesso a programas de saúde prénatal, não podendo assim ter assistência regular durante o período gestacional nem no 
pós-parto, além de terem seus filhos submetidos a condições inadequadas para o nascimento e crescimento.

O uso do habeas corpus coletivo, apesar de não se encontrar estritamente previsto, foi utilizado pelos representantes do CADHu, por ser a única medida possível para combater de forma coletivizada, referida violência que é clara afronta aos direitos humanos e impetrado frente ao STF, teve como relator o ministro Ricardo Lewandowski, e como autoridades coatoras todos os juízes estaduais, federais e distritais, bem como, todos os tribunais de justiça, tribunais regionais federais, além do Superior Tribunal de Justiça.

Enfatizaram o cabimento de habeas corpus coletivo na defesa da liberdade de locomoção de determinados grupos de pessoas, com fulcro na garantia de acesso à Justiça, e considerado o caráter sistemático de práticas que resultam em violação maciça de direitos. Nesse sentido, invocaram o art. 25, I, da Convenção Americana de Direitos Humanos, que garante o direito a um instrumento processual simples, rápido e efetivo, apto a tutelar direitos fundamentais lesionados ou ameaçados.

Expuseram que a competência para julgamento do feito é do Supremo Tribunal Federal, tanto pela amplitude do pedido quanto pelo fato de o Superior Tribunal de Justiça figurar entre as autoridades coatoras.

Ademais, foi alegado que os estabelecimentos prisionais não são preparados de forma congruente para atender à mulher presa, especialmente a gestante e a que é mãe.

Ao arrazoar sobre a legitimidade ativa da ação, o Ministro considerou que por analogia ao mandado de injunção, a competência recai sobre as pessoas arroladas no artigo 12 da lei 13.300/2016, o qual se menciona que o Mandado de Injunção pode ser promovido pelo Ministério Público; por Partido Político com Representação no Congresso Nacional; por Organização Sindical, entidade de classe, ou Associação legalmente constituída a mais de 1 (um) ano; ou então pela Defensoria Pública. Logo, reconheceu a Defensoria Pública da União como legitimada ativa por se tratar de uma ação de alcance nacional. 
Cabe lembrar que o habeas corpus coletivo foi impetrado após ter sido concedida a substituição da prisão preventiva em domiciliar pelo Tribunal Regional Federal da $2^{\text {a }}$ Região, para Adriana Anselmo, esposa do ex-governador do Estado do Rio de Janeiro, sucedendo na forma do inciso V, do artigo 318 do Código de processo Penal. Referido artigo expressa que o Juiz poderá substituir a prisão preventiva pela domiciliar quando o agente for mulher, com filho de ate doze anos e idade incompletos. Diante disso, ficou claro que Adriana não preenchia tais requisitos do artigo já mencionado.

Exteriorizada aplicação inadequada da lei, comprovou a seletividade do Judiciário, pois, de acordo com consulta realizada pelos representantes do CADHu sobre a jurisprudência do Superior Tribunal de Justiça, no site do próprio órgão, constataram referida conversão foi negada a cerca de metade dos casos, sob a justificativa de "considerações sobre as condições pessoais da mulher, apuradas a partir da gravidade do delito supostamente praticado, a alegação de necessidade de prova de inadequação do ambiente carcerário no caso concreto" (HC 143641/SP, 2017, p. 14).

A segunda Turma do Supremo Tribunal Federal analisou o supracitado HC 143641/SP, em fevereiro do ano de 2018 , decidindo por $4 \times 1$ pela substituição da prisão preventiva em domiciliar das pacientes constantes no habeas corpus.

Portanto, o Ministro Lewandowski concordou com o CADHU quanto à competência do STF para julgar tal ação. O magistrado afirmou que tendo em vista a relevância constitucional da matéria, não há como deixar de reconhecer o Supremo Tribunal Federal como autoridade competente para julgar o writ. Além do mais, salientou que a apreciação da referida ação descongestionará consideravelmente o judiciário brasileiro, além de promover a economia e a celeridade processual, princípios dispostos na Constituição Federal de 1988.

Ocupando o polo passivo da ação encontram-se todas as mulheres presas em território nacional, gestantes, puérperas ou mães de crianças até 12 anos. Em seu voto, o Ministro Ricardo Lewandowiski defendeu o cabimento do habeas corpus coletivo 
dizendo que tal instrumento tem como objetivo salvaguardar um dos bens mais preciosos do homem, sendo ele a liberdade.

Outrossim, enfatizou ainda, que devida situação a qual as pacientes se encontram, o habeas corpus na modalidade coletiva talvez seja a única solução viável para assegurar o acesso efetivo à justiça, considerando-se que muitas delas pertencem a grupos mais vulneráveis do ponto de vista econômico.

Em concordância com a decisão do STF, para que fosse realizar a prova de que a criança se encontra sob a responsabilidade da mãe, sendo esse requisito para a aplicação do inciso V, do art. 318 do CPP, bastará a palavra da mãe, a qual deve ser atribuída credibilidade, em caso de dúvida, pode o juiz pedir a realização de um laudo social, sem no entanto, deixar de cumprir a substituição.

Para o Ministro, considerando-se a sociedade atual a qual vivemos, as lesões os direitos são cada vez mais frequentes e assumem proporções coletivas, sendo necessário que o judiciário ofereça um remédio efetivo e compatível para a tutela dos direitos ofendidos. Ademais, pontua que se deve explorar ao máximo as potencialidades do writ, atendendo a proteção dos princípios constitucionais e ao disposto no Pacto de São José da Costa Rica.

Ressalta-se que o Relator trouxe a título de exemplo o afamado o "caso Verbitsky" julgado pela Suprema Corte Argentina. Assim como no Brasil, a nação vizinha também não dispunha de previsão expressa do habeas corpus coletivo. No entanto, a maioria dos membros do Supremo Tribunal da Argentina compreenderam a plausibilidade da ação, tendo em vista à violência aos direitos a serem tutelados, pois os pacientes se encontravam presos e em circunstancias insalubres.

A Procuradoria-Geral da República manifestou-se contrariamente ao cabimento do habeas corpus coletivo, sob o argumento que as pacientes possuem direitos coletivos indeterminados e indetermináveis, e que o habeas corpus tem como finalidade à proteção individual à liberdade de locomoção, impossibilitando assim, a concessão do writ de forma ampla. Para rebater o argumento da falta de identificação das pacientes, o relator imediatamente determinou que fossem identificadas pelo DEPEN (Departamento Penitenciário Federal) todas as mulheres presas 
preventivamente na condição de gestantes ou mães. Desse modo, o Ministro comprovou que é possível discernir os direitos individuais homogêneos das pacientes, anulando assim a argumentação da PGR.

Em consonância com o Ministro, a impetração do remédio na modalidade coletiva vem sido apreciada por outras instâncias como o julgamento do habeas corpus 1080118354-9 julgado pelo Tribunal de Justiça do Rio Grande do Sul e os habeas corpus 207.720/SP e 142.513/ES, ambos julgados pelo Superior Tribunal de Justiça. Constante no acórdão, a Defensoria Pública da União, relembrou que no habeas corpus 118.536 a Procuradoria-Geral da República ofereceu parecer positivo pela concessão da ação coletiva.

Sanadas as imprecisões sobre legitimidades e cabimento da ação, o Ministro Lewandowiski, salientou o quão precário é o sistema prisional brasileiro, sendo lamentavelmente comprovada pela Arguição de Descumprimento de Preceito Fundamental (ADPF) №: 347 MC/DF. Conforme relata o Ministro, os estabelecimentos penitenciários não dispõem de infraestruturas para receber mulheres na condição de gestantes nem tão pouco mães acompanhadas de suas crianças. Desse modo, são impostas às mulheres situações degradantes, sendo elas privadas de atendimentos básicos de pré-natal, pós-parto e ambiente pedagógico para o desenvolvimento das crianças.

Análogo aos dados do Levantamento Nacional de Informações Penitenciárias - INFOPEN, o Relator afirmou que a população absoluta de mulheres encarceradasno sistema penitenciário cresceu 567\% entre os anos de 2000 e 2014, o qual se mostra que tal crescimento e consideravelmente superior em relação a da população masculina. Cabe ressaltar que os dados sobre a infraestrutura em relação a maternidade interior dos estabelecimentos prisionais são bem significativas. Nos estabelecimentos femininos, apenas $34 \%$ possuem cela ou dormitório adequado para gestantes, apenas $32 \%$ possuem berçário e apenas $5 \%$ possuem creches.

Conforme preconiza Lewandowiski (2018) todas essas informações exteriorizadas são especialmente graves, tendo em mente que o Brasil não tem sido capaz de assegurar cuidados relativos à maternidade, nem mesmo às mulheres que 
não estão em situação prisional. É evidente, portanto, que o ambiente carcerário das pacientes não condizem com seus respectivos direitos constitucionais.

Conforme estabelece a Constituição Federal em seu art. $5^{\circ}$, incisos, III, XLVIII, XLIX, variadas vezes a Carta Magna determina o bem-estar das pacientes, prevendo a inadmissibilidade de torturas ou tratamentos desumanos ou degradantes; a não violação dos direitos e liberdades fundamentais; a segurança de que a pena poderá ser cumprida em estabelecimentos distintos de acordo com a natureza do delito e a idade; assegurada também a integridade física e moral das presidiarias.

As prerrogativas inerentes ao tratamento das mulheres que foram inseridas na Lei de Execução Penal pela lei 11.942/2009, como por exemplo o direito da gestante ser acompanhada por médicos, principalmente no pré-natal e no pós-parto, e em seguida a assistência ao recém-nascido. A lei também prevê que os estabelecimentos penais destinados a mulheres deverão possuir berçário, onde as condenadas possam cuidar de seus filhos, inclusive amamentá-los, no mínimo, até seis meses de idade. Além disso, deverá dispor de creche para abrigar crianças maiores de seis meses e menores de sete anos, com a finalidade de assistir a criança desamparada cuja responsável estiver presa.

No que concerne o artigo 227 da Constituição Federal, o qual se refere as crianças, viabiliza que sejam versadas com prioridade absoluta, sendo dever da família, da sociedade e do Estado assegurar à criança, ao adolescente e ao jovem, com absoluta prioridade, o direito à vida, à saúde, à alimentação, à educação, ao lazer. Ademais, o Ministro ressaltou a dura realidade vivenciada pelas gestantes carcerárias, assim como, a falta de assistência durante o pré-natal; a realização de partos realizados em solitárias, corredores e pátios sem qualquer auxílio profissional; e em casos mais extremos, abortos, contágio dos bebês à doenças e óbitos em razão do ambiente insalubre. Diante disso, casos esses se mostram frequente no efêmero prisional.

Portanto, o Ministro pontuou que com a edição do estatuto da primeira infância (Lei 13.257/2016) o artigo 318 do Código de Processo foi alterado no que se refere à prisão preventiva das mulheres mães e gestantes. Conforme preconiza a nova 
redação, o juiz deve substituir a prisão preventiva pela domiciliar quando se tratar de gestantes ou mulheres com filhos de até 12 (doze) anos de idade incompletos.

Por essa razão, o Ministro Ricardo Lewandowiski (2018) julgou procedente que fosse determinado a conversão da prisão preventiva pela domiciliar, sem que houvesse prejuízo da aplicação simultânea das medidas alternativas o qual se estabelece no art. 310 do CPP, onde, coletivamente, todas as mulheres presas, gestantes, puérperas ou mães de crianças e deficientes, nos termos do art. $2^{\circ}$ do ECA e da Convenção sobre Direitos das Pessoas com Deficiências (Decreto Legislativo 186/2008 e lei 13.146/2015), referentes no processo pelo DEPEN e demais autoridades estatuais, durante o tempo em que perdurar tal condição.

Portanto, se exclui os casos de crimes praticados por tais mulheres, sendo eles concretizados mediante violência ou grave ameaça, contra seus descendentes ou, ainda, em situações excepcionalíssimas, as quais deverão ser devidamente fundamentados pelos juízes que o contrapuserem tal benefício.

Diante disso, as alegações denotadas ao final da sessão, o Ministro expandiu o ditame a todas as adolescentes que se encontram inseridas à disposição de medidas socioeducativas dentro do território nacional. Havendo necessidade de iminente cumprimento da ordem, assim,o Ministro determinou que fosse executado de modo integro no prazo máximo de 60 (sessenta) dias, após a publicação, ou seja, até final do mês de abril, referente ao ano de 2017.

Fazendo assim, o nascer e o fruir da justiça coletiva a muito apregoado pelos direitos humanos, onde cada ser tem como axioma máximo a dignidade da pessoa humana.

\section{CONSIDERAÇÕES FINAIS}

O progresso do presente artigo teve o escopo de facilitar a compreensão do instrumento garantidor da liberdade que é o habeas corpus, bem como o cabimento whit em sua condição coletiva. Como o norte, buscou-se esclarecer a seguinte questão: é cabível habeas corpus coletivo no ordenamento jurídico brasileiro? 
A sociedade moderna a qual perduramos tem sido compenetrada na existência de risco, de forma que o progresso de novas tecnologias e a produção padronizada tem criado uma conjuntura propícia à periculosidade e, por conseguinte, expondo a humanidade à violação de seus direitos fundamentais. Determinado risco alcança dimensões coletivas não sendo possível contabilizar o impacto causado a cada indivíduo, tendo por certo que toda a coletividade é impactada de alguma maneira.

Apesar de a legislação pátria antever o habeas corpus como dispositivo garantidor da tutela da liberdade individual, pudemos contemplar que com a realidade da sociedade de risco, as afrontas aos direitos fundamentais têm tomado dimensões coletivas, à vista disso, o judiciário vem sido incitado a responder a esses ataques com dispositivos jurídicos capazes de evitar ou ao menos reduzir os impactos aos direitos coletivos à medida de suas incidências.

Em suma, o resultado do questionamento objeto desse estudo pôde concluir que o habeas corpus coletivo tem sido adotado pela jurisprudência brasileira à medida que a ferramenta se vale para proteger um dos direitos mais importantes do homem, o qual se refere a liberdade. Outrossim, para agir em favor da garantia fundamental de locomoção carece extrair ao máximo os benefícios concedidos pelo habeas corpus, com finalidade de garantir a tutela eficaz e célere do direito.

Portanto, a aplicabilidade do remédio constitucional dado o nome de habeas corpus coletivo é um processo evolutivo no âmbito jurídico brasileiro e de suma importância à sociedade, pois é um aparato célere e eficaz de garantir a liberdade ambulatorial da coletividade, preservando o direito fundamental de cada indivíduo ofendido.

\section{REFERÊNCIAS}

ALMEIDA, Gregório Assagra de. Direito material coletivo - superação da summa divisio direito público e direito privado por uma nova summa divisio constitucionalizada. Belo Horizonte: Del Rey, 2008.

BRASIL. Código Civil; Código Comercial; Código Processo Civil; Constituição Federal. Obra coletiva de autoria da Editora Saraiva com a colaboração de Antonio 
Luiz de Toledo Pinto, Márcia Cristina Vaz dos Santos Windt e Lívia Céspedes. São Paulo: Saraiva, 2005.

(1990). Código de Defesa do Consumidor. http://www.planalto.gov.br/ccivil_03/leis//8078.htm. CDC. Acesso 26 de abril de 2019.

(1988). Constituição Federal.

http://www.planalto.gov.br/ccivil_03/constituicao/constituicao.htm. CF. acesso em 03 de março de 2019.

(1941). Código de Processual Penal.

http://www.planalto.gov.br/ccivil_03/decreto-lei/del3689compilado.htm. CPP. Acesso em 06 de março de 2019.

(1990). Estatuto da Criança e do Adolescente.

http://www.planalto.gov.br/ccivil_03/leis//8069.htm. ECA. Acesso em 10 de maio de 2019.

(2016). Estatuto da Primeira Infância.

http://www.planalto.gov.br/ccivil_03/_Ato2015-2018/2016/Lei/L13257.htm . Acesso em 01 de junho de 2019.

(1984). Lei de Execução Penal.

http://www.planalto.gov.br/ccivil_03/leis/l7210.htm . LEP. Acesso em 01 de junho de 2019.

, Supremo Tribunal Federal. HC o 143.641/SP. Relator Mi. Leonardo Lewandowski. Segunda Turma. Julgado em: 20 de fevereiro de 2018. Disponível em: https://portal.stf.jus.br/processos/downloadPeca.asp?id=15338809875\&ext=.pdf. Acesso em 27 de maio de 2019.

BECK, Ulrich. Sociedade de risco: rumo a uma outra modernidade. São Paulo: 34 Ltda, 2010. Tradução de: Sebastião Nascimento.

CAPEZ, Fernando. Curso de processo penal. 12. ed. São Paulo: Saraiva, 2005.

CUNHA, Mauro; SILVA, Roberto Geraldo Coelho. Habeas corpus no direito brasileiro. Rio de Janeiro: Aide, 1985.

FERREIRA, Pinto. Teoria e prática do habeas corpus. 4. ed. São Paulo: Saraiva, 1988.

GILDDENS, Anthony (1992), As consequências da modernidade. Oeiras: Celta editora. 
LIMA, Thais. Ministros, precisamos falar sobre Habeas Corpus coletivo. Disponível em: https://jota.info/colunas/a-defesa/defesa-senhores-ministrosprecisamos-falar-sobre-habeascorpus-coletivo-22092016. Acesso em 24/04/2019

LOPES Jr., Aury. Direito Processual Penal. 11ํed. São Paulo: Saraiva 2014.

MOSSIN, Heráclito Antônio. Habeas corpus: antecedentes históricos, hipóteses de impetração, processo, competência e recursos, modelos de petição e jurisprudência. São Paulo: Atlas, 1995.

MIRABETE, Júlio Fabbrini. Processo Penal. 17. ed. São Paulo: Atlas, 2005.

PINHO, Rodrigo César Rebello. Teoria geral da Constituição e Direito Fundamentais. 6. ed. São Paulo: Saraiva, 2006.

PONTES DE MIRANDA. História e prática do Habeas-corpus. 3.ed. Rio de Janeiro: José Konfino, 1955.

SILVA, José Afonso da. Curso de direito constitucional positivo. 33.ed. São Paulo: Malheiros Editores, 2010.

SIQUEIRA, Galdino. Curso de processo criminal. 2ed. São Paulo:

Magalhães,1930.p.383384).http://www.uit.br/mestrado/images/dissertacoes/22014/H ABEAS\%20CORPUS\%20COLETIVO-Lilian-nassara.pdf > acesso em: 06 abril de 2019. 